\title{
A FORMA DE ACESSO AO ENSINO SUPERIOR NAS UNIVERSIDADES PÚBLICAS: JUSTIÇA, MÉRITO, ESFORÇO E OPORTUNIDADES
}

\author{
* Riva Sobrado de Freitas ${ }^{1}$ \\ ** Daniela Zilio ${ }^{2}$
}

\begin{abstract}
Resumo: A forma mais usual de acesso ao ensino superior público no Brasil ainda é o vestibular tradicional. Assim, o objetivo do presente ensaio é questionar a forma de acesso ao ensino superior nas universidades públicas brasileiras, especificamente na modalidade dos vestibulares, indagando a justiça e o mérito envolvido na seleção dos aprovados. Para tanto, a presente pesquisa é de coleta bibliográfica exploratório-explicativa, qualitativa, e utiliza o método dedutivo de análise.
\end{abstract}

Palavras-chave: Ensino superior público. Esforço. Justiça. Mérito. Oportunidades.

\section{THE FORM OF ENTRY TO HIGHER EDUCATION IN PUBLIC UNIVERSITIES: FAIRNESS, MERIT, EFFORT AND OPPORTUNITIES}

\begin{abstract}
The most usual way of accessing public higher education in Brazil is still by the traditional examination called "vestibular". Thus, the present paper aims to question the form of entry to higher education in public Brazilian Universities, specifically by the "vestibulares", considering the fairness and the merit involved in the selection of the approved candidates. To achieve the intent, it was done a bibliographic exploratory-explanatory research, qualitative, using the deductive method.
\end{abstract}

Keywords: Higher education. Effort. Fairness. Merit. Opportunities.

\section{INTRODUÇÃO}

O presente ensaio tem como objetivo central a análise do mérito no panorama da justiça em algumas de suas teorias, questionando-o especificamente quanto ao acesso ao ensino superior público no Brasil. Assim, justifica-se na medida em que a análise da justiça e de suas teorias (ou pelo menos de alguma delas), sobretudo partindo-se de problemas práticos como é

\footnotetext{
1 * Pós-doutora em Direito pela Universidade de Coimbra; Doutora e Mestre em Direito pela Pontifícia Universidade Católica de São Paulo; Professora e pesquisadora do Programa de Pós-Graduação em Direito da Universidade do Oeste de Santa Catarina (UNOESC - Chapecó/SC). Professora Adjunta Aposentada de Direitos Humanos da Universidade Estadual Paulista "Júlio de Mesquita Filho" (UNESP) - Campus Franca (São Paulo). Chapecó-SC. E-mail: rivafreit@gmail.com.

$2 * *$ Doutoranda e Mestre em Direito pela Universidade do Oeste de Santa Catarina. Especialista em Direito Civil e Direito Processual Civil pela Universidade do Oeste de Santa Catarina e Especialista no Novo Sistema Processual Civil Brasileiro pela Universidade do Oeste de Santa Catarina. Professora. Advogada. Pesquisa realizada com o apoio da Universidade do Oeste de Santa Catarina. Chapecó-SC. E-mail: danielazilio@ yahoo.com.br.
} 
o intuito, promove debates que levam a caminhos de melhoramento da realidade posta, ou pelo menos são tentativas de fazê-lo. A reflexão é, pensa-se, sempre benéfica.

Evidentemente, discutir a justiça não é um caminho linear. Como se sabe, a justiça pode assumir diversas formas, a depender do contexto prático em que está inserida, como aufere-se perfeitamente no trabalho de Miller (2017), e o estudo do que é justo ou de alguma das teorias acerca da justiça demanda cuidado. Nesta senda, como autores de base para a discussão exposta, serão utilizados Argelina Cheibub Figueiredo e John Rawls, prioritariamente quando o assunto é o mérito, conceito muito importante para a discussão proposta.

O problema a ser desafiado, então, calca-se no questionamento acerca da justiça ou injustiça na forma de acesso hoje utilizada pelas instituições de ensino superior público como principal forma de acesso: os vestibulares tradicionais, que são embasados essencialmente no mérito como resultado. Partindo do objetivo geral, coadunado na análise acerca da justiça do caso exposto, chega-se aos objetivos específicos, quais sejam: ponderação da justiça e do mérito de forma genérica; e explicitação dos conceitos relacionados essencialmente ao problema de pesquisa, que é o acesso ao ensino superior público. Reitera-se desde já que o presente trabalho não tem o condão de realizar pesquisa quantitativa para conhecer o padrão de ingressantes, o que se almeja é teoricamente traçar uma linha de raciocínio argumentativo acerca do mérito (sobretudo enquanto resultado) dentro do espectro exposto.

O trabalho será formalmente estruturado de forma a inicialmente a argumentação voltar-se genericamente à justiça e ao conceito de mérito, para após, adentrar ao objeto específico de análise, qual seja, o mérito no acesso ao ensino superior público. A pesquisa é de coleta bibliográfica exploratório-explicativa, qualitativa, com o emprego do método dedutivo de análise, não almejando esgotar o tema, mas propor um novo modo de debate.

\section{A JUSTIÇA E A DEFINIÇÃO DE MÉRITO}

Conforme explicitado no introito do presente ensaio, a explicitação da justiça e do mérito parte da análise de referenciais específicos. Inicialmente, então, há a necessidade de que, ainda que de forma sucinta, as ideias conceituais sejam devidamente esclarecidas, sobretudo do ponto de vista dos autores de base consultados.

Assim, Argelina Cheibub Figueiredo, em seu trabalho "Princípios de Justiça e avaliação de políticas”, analisa a ideia do princípio de mérito enquanto princípio de justiça

Rev. de Teorias da Justiça, da decisão e da argumentação jurídica | e-ISSN: 2525-9644| Evento Virtual| v. 6 | n. 1 | p. 37-54| Jan/Jun. 2020 
distributiva. Veja-se que, a partir do ideal do princípio de mérito, pode-se questionar também a forma de ingresso regularmente realizada pelas instituições de ensino superior públicas no País, a fim de avaliar possíveis "injustiças" estruturais, conforme se verificará no momento oportuno.

Pois bem, Argelina Cheibub Figueiredo (1997) quando cuida do tema, intenta, como a autora mesmo argumenta, tratar de concepções de justiça social, bem como de modelos de justiça social, questões que, como argumenta, na bibliografia sobre o assunto normalmente há o estudo de forma independente, e ela o faz, de modo a questionar (quanto ao mérito) a concepção do mérito enquanto resultado em contraposição ao mérito enquanto esforço.

Sendo dessa forma, ao adentrar nas questões específicas da justiça social, a autora aduz ser ela um atributo das instituições sociais que determinam o acesso, ou pelo menos as possibilidades de, daqueles que estão inseridos em uma sociedade, a recursos que podem ser considerados meios para a satisfação de uma grande quantidade de desejos. A formulação original de tal ideal advém da teoria de Brian Barry ${ }^{3}$.

Ainda, Figueiredo (1997) explicita que as noções do que ela chama de justiça formal e de justiça substantiva devem ser ponderadas. Traçando-se um paralelo com os planos de igualdade, normalmente vinculados ao direito constitucional, a ideia de justiça formal remete à igualdade formal (do artigo $5^{\circ}$, caput, da Constituição Federal, que determina que todos são iguais perante a lei sem distinção de qualquer natureza) e a ideia de justiça substantiva remete à igualdade material ou substancial (de tratar os desiguais na medida se suas desigualdades pensamento advindo ainda dos ideais de Aristóteles). Para Figueiredo (1997), assim, a justiça formal tem sua importância na medida em que garante, ou pelo menos se aproxima, da noção de imparcialidade jurídica. Porém, a autora determina que a despeito de a imparcialidade ter seu valor, não explica e estabelece um parâmetro levando em consideração as condições diferentes de cada escala de membros de um determinado contexto. Daí a relevância da justiça substantiva sobre a qual se debruça a autora a ponderar.

Neste sentido, a autora explana a justiça "distributiva" a partir de três princípios distintos, quais sejam: princípio de direito, princípio de mérito, e princípio de necessidade. Sendo assim, o presente ensaio intenta colocar em pauta o princípio de mérito, busca explanálo e contestá-lo, para então investigar a resposta ao questionamento que se faz acerca do acesso à educação e a "justiça" ou "injustiça" no sistema brasileiro de ingresso no ensino superior público, hoje configurado sobretudo sob a forma de vestibular(es).

${ }^{3}$ Theories of Justice, 1989.

Rev. de Teorias da Justiça, da decisão e da argumentação jurídica | e-ISSN: 2525-9644| Evento Virtual| v. 6 | n. 1 | p. 37-54| Jan/Jun. 2020 


\section{A FORMA DE ACESSO AO ENSINO SUPERIOR NAS UNIVERSIDADES PÚBLICAS: JUSTIÇA, MÉRITO, ESFORÇO E OPORTUNIDADES}

Em seus estudos, Figueiredo (1997) menciona que o princípio de mérito é aquele que, em tese, melhor realiza a noção de justiça. Ademais, embasada claramente em Brian Barry, a autora menciona a importância de fatos e características de cada qual, e a questão das ações e do esforço dos indivíduos na configuração do mérito. Veja-se que não há no senso comum uma solução pacífica quanto ao esforço e ao resultado na aferição do mérito pois, assim como não seria prudente desconsiderar o esforço, desconsiderar o resultado, ou subjugá-lo, também não parece apropriado (a autora cita o exemplo de que parece absurdo pagar um homem mais do que outro por fazer um trabalho porque o primeiro apesar de mais vagaroso e com pior resultado, necessita de mais esforço para realizá-lo). Para tentar solucionar o exposto, pode-se citar Brian Barry (1989), na medida em que este sugere que fatores externos como sorte estão envolvidos no dilema, e, ainda, que para a discussão do mérito é imprescindível considerar a origem das capacidades e oportunidades; não menos importante, precisa-se manter a vinculação de mérito a esforço, de modo que se verifique a questão do mérito levando em consideração o fato de que o indivíduo poderia ter feito outra coisa.

Quanto à justiça e ao mérito para John Rawls (2003), veja-se que o autor busca a definição de uma justiça que seja equitativa ${ }^{4}$, ou seja, materialmente igualitária, partindo do pressuposto da existência de um acordo mínimo tomado dentro do que ele denominou de "posição original” (esses conceitos serão retomados, ainda que concisamente, adiante, mas esclarece-se desde já que para John Rawls há a ideia de um acordo justo, equitativo, entre pessoas livres e iguais, em uma posição original onde as partes não conhecem as posições sociais ou doutrinas abrangentes específicas das pessoas que elas representam, não conhecem o seu papel, posição, ignoram raça, dons naturais, aliás, não se permite que elas os conheçam) (RAWLS, 2003, p. 21). O autor constrói o seu pensamento a partir da ideia de uma sociedade enquanto sistema equitativo de cooperação (social) $)^{5}$.

\footnotetext{
${ }^{4}$ John Rawls deixa muito claro que, a justiça como equidade parte de uma concepção política, e não metafísica, e é a partir daí que se constrói o argumento exposto no texto.

${ }^{5} \mathrm{O}$ autor cita que são fundamentais as ideias utilizadas para organizar e dar uma estrutura ao conjunto da teoria da justiça como equidade, de modo que, a ideia mais fundamental nessa concepção de justiça é a ideia de sociedade como sistema equitativo de cooperação social que se perpetua de uma a outra geração (RAWLS, 2003). Segundo ele, essa ideia central é elaborada em conjunto com suas outras ideias fundamentais: a ideia de cidadãos que cooperam entre si enquanto pessoas livres e iguais, e a ideia de uma sociedade bem ordenada, regulada por aquilo que o autor elenca como uma concepção pública de justiça. Quanto ao sistema equitativo de cooperação social, o autor faz questão de referir-se à ideia dessa forma, uma vez que, a cooperação por si não necessariamente é equitativa, mas para Rawls e para a teoria por ele aventada, as contribuições e recebimentos precisam ser, de modo que a cooperação é, dentro da perspectiva de sua teoria, equitativa.
}

Rev. de Teorias da Justiça, da decisão e da argumentação jurídica | e-ISSN: 2525-9644| Evento Virtual| v. 6 | n. 1 | p. 37-54| Jan/Jun. 2020 
Inicialmente, mister que se esclareça que, para que se chegue à ideia de "justiça como equidade", é necessário que se especifique os princípios de justiça de John Rawls, e para tanto, deixa-se muito claro, parte-se do ideal previsto pelo autor na obra "Justiça como equidade: uma reformulação", eis que, como ele próprio argumenta, na obra citada houve uma "revisão" dos dois princípios de justiça discutidos na obra "Uma Teoria da Justiça", de 1971 (portanto, evidentemente anterior à obra consultada, que, como o título propõe, foi uma reformulação).

Para John Rawls, existem dois princípios de justiça, e o segundo deles subdivide-se em mais dois; ainda, o primeiro princípio tem precedência sobre o segundo, de modo que eles devem ser vislumbrados sequencialmente. Assim, para Rawls (2003, p. 60):

\begin{abstract}
“(a) cada pessoa tem o mesmo direito irrevogável a um esquema plenamente adequado de liberdades básicas iguais que seja compatível com o mesmo esquema de liberdade para todos; e (b) as desigualdades sociais e econômicas devem satisfazer duas condições: primeiro, devem estar vinculadas a cargos e posições acessíveis a todos em condições de igualdade equitativa de oportunidades; e, em segundo lugar, têm de beneficiar ao máximo os membros menos favorecidos ${ }^{6}$ da sociedade (o princípio da diferença) $)^{7 ”}$
\end{abstract}

É claro que, na teoria de John Rawls, como o próprio argumenta, parte-se de uma concepção ideal, centralizada em uma posição original em que as pessoas estão em estado de neutralidade sob o que ele denomina de "véu da ignorância"8. Assim, no que concerne à pauta aqui apresentada, adiante se buscará averiguar a forma de acesso ao ensino superior à luz (também) dessa teoria (Teoria da Justiça revisitada enquanto Justiça como Equidade) e levandose em consideração o véu da ignorância, pelo menos em tese ${ }^{9}$. Veja-se que, como primeiro princípio de uma sociedade justa, John Rawls, estatui uma igual liberdade para todos (aquilo

\footnotetext{
${ }^{6} \mathrm{O}$ autor se volta para o conceito de "menos favorecidos" na parte II, § 17, da obra em comento (Justiça como equidade: uma reformulação), especificamente entre as páginas 81 e 86 e liga, em síntese, a ideia de menos favorecidos à ideia de acesso a bens primários - direitos e liberdades básicas; liberdades de movimento e de livre escolha de ocupação sobre um fundo de oportunidades diversificadas, oportunidades estas que propiciam a busca de uma variedade de objetivos e tornam possíveis as decisões de revê-los e alterá-los; os poderes e prerrogativas de cargos e posições de autoridade e responsabilidade; renda e riqueza; e bases sociais e autorrespeito, entendidas como aqueles aspectos das instituições básicas normalmente essenciais para que os cidadãos possam ter um acesso vívido de seu valor enquanto pessoas e serem capazes de levar adiante seus objetivos com autoconfiança (grifo nosso).

${ }^{7}$ Para muitos estudiosos de John Rawls, os termos "princípio maximin" ou "justiça maximin" deveriam ser usados no lugar de "princípio da diferença".

${ }^{8}$ John Rawls destaca que um dos motivos pelos quais as características e circunstâncias particulares de cada pessoa devem ser abstraídas na posição original da estrutura básica é que devem ser eliminadas possíveis posições vantajosas de negociação que surgem como resultado de "tendências sociais e históricas cumulativas" (RAWLS, 2003, p. 22).

${ }^{9}$ Veja-se que o autor especifica que a qualquer momento se pode voltar à posição original e ponderar a justiça a partir do véu da ignorância, por tratar-se, inclusive, de uma teoria ideal, de modo que não há nenhum problema em pensar-se nos temas sociais de hoje a partir do plano Rawlsiano.
}

Rev. de Teorias da Justiça, da decisão e da argumentação jurídica | e-ISSN: 2525-9644| Evento Virtual| v. 6 | n. 1 | p. 37-54| Jan/Jun. 2020 


\section{A FORMA DE ACESSO AO ENSINO SUPERIOR NAS UNIVERSIDADES PÚBLICAS: JUSTIÇA, MÉRITO, ESFORÇO E OPORTUNIDADES}

que se pode chamar de liberalismo igualitário), e como segundo princípio, o autor propõe que as desigualdades sociais e econômicas podem existir desde que cargos e posições sejam acessíveis a todos em condições de igualdade equitativa de oportunidades, e que beneficiem ao máximo os menos favorecidos da sociedade (aquilo que se pode chamar de princípio da diferença).

Finalmente, verificadas as acepções de justiça e de mérito, no momento que segue o estudo se voltará para a análise dos termos especificamente dentro do problema de pesquisa proposto, ou seja, intentar-se-á questionar a justiça nos hodiernos meios de acesso ao ensino superior público, colocando no centro da argumentação, o mérito.

\section{O ACESSO AO ENSINO NAS INSTITUIÇÕES PÚBLICAS DE ENSINO SUPERIOR: JUSTIÇA E MÉRITO?}

Sabe-se que o direito à educação é direito humano ${ }^{10}$ fundamental (social) ${ }^{11}$, previsto genericamente no artigo $6^{\mathrm{o} 12}$, caput, e especificamente no $\operatorname{artigo} 205^{13}$ e seguintes da

\footnotetext{
${ }^{10}$ Tratando-se do direito à educação enquanto direito humano, insta relacionar que a Declaração Universal dos Direitos Humanos de 1948 aduz, em seu artigo XVI que: "Toda a pessoa tem direito à educação. A educação deve ser gratuita, pelo menos a correspondente ao ensino elementar fundamental. $\mathrm{O}$ ensino elementar é obrigatório. $\mathrm{O}$ ensino técnico e profissional deve ser generalizado; o acesso aos estudos superiores deve estar aberto a todos em plena igualdade, em função do seu mérito. A educação deve visar à plena expansão da personalidade humana e ao reforço dos direitos do Homem e das liberdades fundamentais e deve favorecer a compreensão, a tolerância e a amizade entre todas as nações e todos os grupos raciais ou religiosos, bem como o desenvolvimento das atividades das Nações Unidas para a manutenção da paz. Aos pais pertence a prioridade do direito de escolher o gênero de educação a dar aos filhos" (grifo nosso). Note-se que a Declaração menciona claramente que o ensino superior deve ser disponibilizado a todos, em plena igualdade, em função do seu mérito. Ocorre que é justamente esse "mérito" que se busca discutir: qual é a melhor forma de averiguar o mérito (esforço/resultado)? Ademais, a expressão "em plena igualdade", também é objeto de discussão no presente ensaio: é equitativamente igualitário (retomando a justiça formal e a justiça substantiva) que se meça a qualidade de todos os estudantes da mesmíssima forma? Levando-se em consideração a bibliografia de base estudada, conjugada à igualdade material estatuída pela própria ordem constitucional (em termos de Brasil), parece não ser o caso. Igualmente, o Protocolo de São Salvador, documento internacional do qual o Brasil é signatário, aduz em seu artigo 13, 3, "c", que: "o ensino superior deve tornar-se igualmente acessível a todos, de acordo com a capacidade de cada um, pelos meios que forem apropriados e, especialmente, pelo estabelecimento progressivo do ensino gratuito". Percebe-se que, o termo "de acordo com a capacidade de cada um", traz à tona a ideia do mérito exposta também na Declaração Universal, mas, o conceito e a forma de aferição do mérito, como exposto, podem ser questionados. Ademais, o próprio Protocolo menciona a necessidade de que o ensino seja (progressivamente) gratuito, o que certamente leva a crer que camadas menos "abastadas" da população precisam ser contempladas.

${ }^{11}$ Devido ao corte metodológico feito, não se intenta aqui fazer a diferenciação entre direitos humanos e direitos fundamentais.

${ }^{12}$ Art. $6^{\circ}$ São direitos sociais a educação, a saúde, a alimentação, o trabalho, a moradia, o transporte, o lazer, a segurança, a previdência social, a proteção à maternidade e à infância, a assistência aos desamparados, na forma desta Constituição. (Redação dada pela Emenda Constitucional n ${ }^{\circ}$ 90, de 2015).

13 Art. 205. A educação, direito de todos e dever do Estado e da família, será promovida e incentivada com a colaboração da sociedade, visando ao pleno desenvolvimento da pessoa, seu preparo para o exercício da cidadania e sua qualificação para o trabalho.
}

Rev. de Teorias da Justiça, da decisão e da argumentação jurídica | e-ISSN: 2525-9644| Evento Virtual| v. 6 | n. 1 | p. 37-54| Jan/Jun. 2020 
Constituição Federal ${ }^{14}$. Muito bem, o sistema de ingresso dos estudantes ao ensino superior público no Brasil (tratando da regra geral) se dá por meio de uma prova escrita, composta de questões objetivas (de múltipla escolha) e de redações (às vezes questões de cunho subjetivo) em que, o candidato que mais questões "acerta", mais sucesso tem, conquistando o tão almejado espaço na universidade. Assim, questiona-se, na relação esforço/resultado exposta, e efetivamente levantada por Brian Barry (1989)-, levando-se em consideração a justiça substantiva, também estudada por Figueiredo (1997), e as formulações de justiça como equidade de John Rawls: tal forma de acesso, que desconsidera alguns tipos de esforços dos estudantes, é uma forma de realização da justiça, de modo a ser uma forma justa de "escolha" dos candidatos aprovados? Veja-se, de forma alguma o presente ensaio tem o intento de desprezar o mérito (com o perdão do "necessário" pleonasmo) dos estudantes que acertaram mais questões, ou que melhor "se deram" (mérito pelo resultado) nas provas e porquanto atingiram a sua vaga nas universidades.

O que se questiona é: por que não um sistema de acesso ao ensino superior público em que a vida pregressa do estudante (o seu esforço, o caminho que ele precisou trilhar para chegar até o momento do possível ingresso) seja levado em consideração? Ou seria acertado dizer que um jovem, negro, morador da periferia e estudante de escola pública tem condições equitativas de buscar uma vaga nas universidades que um jovem, branco, morador de áreas nobres de grandes cidades, e que teve acesso aos melhores colégios e cursos?

Veja-se que aqui não se questiona a efetividade ou o mérito das cotas, que inegavelmente são ações afirmativas que buscam equilibrar as desigualdades, em prol da igualdade material, auxiliando sobremaneira na busca por um sistema mais equitativo de oportunidades. Elas já o vêm fazendo e, inclusive, aufere-se da Lei n. 12.711/2012 $2^{15}$, do decreto

${ }^{14}$ Aqui também não se intenta questionar a obrigatoriedade de ensino ou a sua universalização. É evidente que a
Carta Magna tem a preocupação voltada ao ensino básico, sobretudo ao ensino fundamental, mas, a despeito da
não referência explícita, evidentemente o direito fundamental à educação contempla o ensino superior.
${ }^{15}$ Veja-se que, antes mesmo da Lei $12.711 / 2012$, algumas universidades públicas já tinham programas internos de
cotas. De acordo com Ivan Siqueira (USP), já no ano de 2002, a Universidade Estadual do Rio de Janeiro (Uerj)
adotou um programa de cotas étnico-raciais com $20 \%$ das vagas para pretos e pardos; $20 \%$ para estudantes de
escola pública; e $5 \%$ para portadores de necessidades especiais (JORNAL DA USP ESPECIAL, S.D). Inclusive,
no dia 26 de abril de 2012 , o Supremo Tribunal Federal julgou a Arguição de Descumprimento de Preceito
Fundamental n. 186, sobre a política de instituição de cotas raciais pela Universidade de Brasília (UnB). O
requerente foi o partido Democratas (DEM). A UnB implantou sistema próprio de cotas em 2004. Questionadas,
as cotas foram julgadas plenamente constitucionais, à ocasião, pela corte máxima, formalizando precedente. Aliás,
nos votos dos Ministros julgadores, percebe-se a repetição da expressão "igualdade material ou substancial", ou
seja, ao entenderem acerca da constitucionalidade das cotas, eles levaram em consideração a igualdade material
preconizada de forma global pela Constituição Federal de 1988, buscando, a bem da verdade, um sistema
equitativo de oportunidades. Rev. de Teorias da Justiça, da decisão e da argumentação jurídica | e-ISSN: 2525-9644| Evento Virtual| v. 6 | n. 1 | p. 37-54| Jan/Jun. 2020 


\section{A FORMA DE ACESSO AO ENSINO SUPERIOR NAS UNIVERSIDADES PÚBLICAS: JUSTIÇA, MÉRITO, ESFORÇO E OPORTUNIDADES}

7.824/2012, e da Portaria Normativa 18/2012 do Ministério da Educação, a real possibilidade de que, a médio e longo prazo, elas possam ser uma provável solução ao embate proposto ${ }^{16}$, muito embora na prática uma série de problemas já tenham sido detectados. Ocorre que, a despeito disso, é preciso insistir no argumento acerca do vestibular, da prova de fato (que pretende avaliar a "aptidão" do estudante para futuramente estar ou não na universidade), que em um dia (ou em alguns dias), intentam medir e aferir o melhor resultado, o estudante que mais acerta questões, desconsiderando todo o caminho que ele precisou trilhar para chegar até ali. Não seria melhor, ou mais adequado, levar em consideração - ao menos em alguns casos o esforço para o ingresso a tais instituições (sobretudo públicas, onde o Estado tem papel primordial)? Parece ser uma discussão justa ${ }^{17}$, até porque uma maior quantidade de negros, de indígenas, de pessoas de classes sociais mais baixas, de moradores de periferias, e inúmeros outros exemplos, tornaria o próprio mercado de trabalho mais diversificado e democratizante, como já pontuado pelo professor Leonardo Avritzer, da Universidade Federal de Minas Gerais - UFMG, quando instado a se manifestar acerca das ações afirmativas na ocasião do julgamento da Arguição de Descumprimento de Preceito Fundamental n. 186 (ADPF das cotas raciais da Universidade de Brasília - UnB). Veja-se, não que as cotas já não o façam, mas não se sabe se seria prudente confiar que somente elas erradicariam o problema social envolvido.

É claro que, existem outros modos de ingressar na universidade pública, para além do vestibular tradicional e, muito provavelmente, esses outros modos até sejam meios (ou pelo menos tentativas de) desfazimento do padrão de mérito pelo resultado. São exemplos de modos de acesso ao ensino superior público: vestibular com provas de habilidades específicas; vestibular continuado, ou seja, dividido em etapas anuais; Exame Nacional do Ensino Médio Enem $^{18}$, por meio do Sistema de Seleção Unificada (Sisu), que é um sistema de seleção que

\footnotetext{
${ }^{16}$ Há a garantia de reserva de 50\% das matrículas por curso e turno em universidades e institutos federais, a alunos que tenham cursado o ensino médio integralmente em escolas públicas (há ainda subdivisões internas que levam em consideração o fator social - renda, e o fator racial). A ideia inicial foi a aplicação gradual do definido em lei. As cotas valem para vestibulares tradicionais e Sisu (MINISTÉRIO DA EDUCAÇÃO, 2012).

17 À guisa de conhecimento e esclarecimento, veja-se a pesquisa divulgada pela Esalq - USP (Escola Superior de Agricultura "Luiz de Queiroz" da Universidade de São Paulo) acerca do perfil dos seus ingressantes no ano de 2019 (a pesquisa englobou os cursos de Administração; Ciências Biológicas; Ciências dos Alimentos; Ciências Econômicas; Engenharia Agronômica; Engenharia Florestal e Gestão Ambiental, com ingresso pelo Enem - Sisu, e vestibular - Fuvest): quanto à cor da pele - 76,5 eram brancos, 15,0\% eram pardos, 4,6\% eram negros e 3,8\% eram amarelos; quanto ao ensino médio - 57,4\% estudaram em escolas particulares, $39,1 \%$ em escolas públicas, e $3,6 \%$ em escolas públicas e particulares; quanto ao trabalho - $94 \%$ não trabalhavam, $4,4 \%$ trabalhavam em tempo parcial, e 1,6\% trabalhavam em tempo integral.

${ }_{18}$ Mesmo o ENEM, embora possa parecer mais democrático do ponto de vista da inclusão, exterioriza, ao contrário, também o mérito pelo resultado. De acordo com o sítio eletrônico da revista Exame (2019), no ano de 2017, 1 a cada 600 alunos pobres conseguiu ficar entre os "melhores" no exame, que é utilizado como forma de Rev. de Teorias da Justiça, da decisão e da argumentação jurídica | e-ISSN: 2525-9644| Evento Virtual| v. 6 | n. 1 | p. 37-54| Jan/Jun. 2020
} 
leva em conta o desempenho que o candidato teve no exame; ou até mesmo utilização da nota do Enem como parte integrante da nota final do vestibular (GUIA DO ESTUDANTE, 2019). Ocorre que, ainda hoje parece que a maior parte dos ingressantes (inclusive pelos meios aqui citados) faz parte de um grupo que teve melhores oportunidades desde a primeira infância ${ }^{19}$.

Não se pode deixar de mencionar que, o acesso às instituições privadas de ensino costuma ser mais "fácil", ou no mínimo menos dificultoso, de primeiro plano pela menor (em regra) relação candidato/vaga, e depois, porque as instituições privadas costumam, atualmente, realizar processos seletivos simplificados, vestibulares agendados, provas eletrônicas, ingresso pela análise do currículo/histórico escolar, enfim, as provas têm sido menos excludentes a depender do sentido que se visualize o problema. Mas, o ensino ainda assim não é o bastante democrático e acessível, na medida em que nem de perto todos os estudantes conseguem arcar com os custos de um curso superior privado, tampouco sua família, e, da mesma forma, poucos são os que conseguem bolsas (pelo Prouni - Programa Universidade para Todos -, vinculado ao Enem, onde o que pesa, também, é a nota alcançada neste) ou financiamentos (o Fies - Fundo de Financiamento Estudantil, igualmente é vinculado ao Enem). Atente-se que, não se está afirmando que os programas citados não tenham melhorado a situação ou ajudado de alguma forma na democratização das oportunidades, mesmo porque é nítido que caso eles não existissem, até a forma pela qual a educação superior é vista hoje seria diferente, e que bom que eles existem, e que pessoas outrora impossibilitadas podem galgar vagas em instituições privadas. Mas, entende-se que o mérito pelo resultado persiste, apesar de todas as melhorias citadas, também no ensino privado, mas prioritariamente no ensino público, objeto da discussão, e que deveria ser inclusivo e jamais excludente.

Veja-se, concorda-se com Brian Barry (1989) quando o autor menciona que levar em consideração somente o esforço, e não o resultado, não seria a atitude mais correta de qualquer dos pontos de vista (formal e substancial). O problema é, no caso estudado, levar em

acesso tanto para instituições públicas quanto para instituições privadas. Nesta senda, os fatores socioeconômicos corresponderiam ao peso de cerca de $85 \%$ do resultado de quem presta a prova. De acordo com a notícia, o levantamento foi feito pelo cientista Leonardo Sales. É claro que, foram consideradas condições extremas, tais quais não possuir internet ou telefone fixo, ter estudado em escola pública com pouca infraestrutura, e a família não possuir carro ou computador, mas não se pode negar que os números são esclarecedores.

${ }^{19} \mathrm{O}$ presente texto é dissertativo-argumentativo, porquanto não tem o intuito de pesquisar quantitativamente qual é o perfil dos ingressantes em instituições públicas de ensino. Parece ser evidente, porém, o raciocínio que foi construído, de discussão em relação ao mérito enquanto resultado, e a possibilidade de que certos perfis de candidatos sejam preteridos em provas e vestibulares, não por sua condição, mas pela impossibilidade (temporária, talvez) de se igualar aos demais candidatos.

Rev. de Teorias da Justiça, da decisão e da argumentação jurídica | e-ISSN: 2525-9644| Evento Virtual| v. 6 | n. 1 | p. 37-54| Jan/Jun. 2020 


\section{A FORMA DE ACESSO AO ENSINO SUPERIOR NAS UNIVERSIDADES PÚBLICAS: JUSTIÇA, MÉRITO, ESFORÇO E OPORTUNIDADES}

consideração somente o resultado, à margem do esforço, e se diz isso sobretudo levando-se em consideração a justiça social, conforme relaciona Figueiredo (1997).

Acordar às 6 (seis) horas da manhã, trabalhar o dia inteiro (muitas vezes na informalidade), estudar à noite (ensino médio) e disputar de igual para igual uma vaga com alguém que "só" (assim mesmo entre aspas porque estudar já é muito) estuda, e sempre teve as melhores oportunidades, de fato não parece levar em consideração uma justiça substancial, tampouco caso se tenha em mente o princípio de justiça distributiva conhecido como mérito. Tudo bem que esses são os extremos, e no meio deles há uma infinidade de indivíduos (nem tão "ao céu" e nem tão "ao inferno"), mas é preciso questionar-se sobre, e de forma urgente pois, apesar de aparentemente mais acessível do que foi outrora, o ensino superior ainda é realidade para poucos, para muito poucos, na imensidão do País.

Parece que, talvez, o mais sensato, ou até mesmo mais justo, seria levar em consideração sim o resultado (para não se correr o risco de cometer injustiças a pretexto de exercer a justiça), mas propor um sistema de avaliação que não desprezasse a vida pregressa do candidato, os esforços, como mencionado por Figueiredo (1997), atentando-se a um equilíbrio entre esforço/resultado (algo muito difícil até mesmo na teoria), para que não somente aquele que "chega mais longe" seja o "premiado" com perspectivas, mas também aquele que "corre mais", que teve um ponto de partida infinitamente mais distante do que aquele que por mérito próprio (qual é o conceito de mérito mesmo?), chegou mais longe, mas que teve o ponto de partida muito reduzido, ou reduzido mesmo que parcialmente única e exclusivamente por ter nascido "agraciado".

Aqui, chega-se a um ponto crucial da argumentação: o que de fato é o mérito? Seria ele um conceito subjetivo? Deve ele levar em consideração o esforço (quem corre mais), ou somente o resultado (quem chega mais longe)? É essa a discussão apontada por Figueiredo (1997), e a autora traz uma espécie de solução a partir de Brian Barry (1989) que já foi exposta alhures e que se retoma agora com o intuito de engrandecer o argumento e acirrar a discussão: 1 - fatores externos como sorte estão envolvidos no dilema; 2 - é necessário considerar a origem das capacidades e oportunidades; 3 - existe a possibilidade de manter o ponto essencial da vinculação de mérito a esforço, tornando condição necessária para aferição do mérito o fato de que a pessoa poderia ter feito outra coisa (a exemplo de dois nadadores, um profissional e outro não, que buscam salvar alguém que está se afogando - é óbvio que aquele que não é profissional se esforçará mais, mas há que ser levada em consideração a variável de que ambos poderiam

Rev. de Teorias da Justiça, da decisão e da argumentação jurídica | e-ISSN: 2525-9644| Evento Virtual| v. 6 | n. 1 | p. 37-54| Jan/Jun. 2020 
ter feito absolutamente nada, nem tentar o salvamento). Assim, o que parece razoável é que no caso em questão, ambas as variáveis sejam levadas em consideração para a solução da equação, ao menos tentando equilibrar esforço/resultado (como dito, não se pretende desprezar o resultado), para que mais pessoas, com diferentes características, histórias de vida, pontos de partida, origem social e étnica, alcancem o intento do ensino superior público, por meio de uma justiça distributiva sim, mas eminentemente substancial.

Assim sendo, a ideia do princípio de mérito, exposto por Brian Barry (1989) e também por Argelina Cheibub Figueiredo (1997), relaciona muito bem esforço e resultado, indagando o mérito exposto enquanto um princípio de justiça distributiva, e ponderar o direito à educação, especificamente o acesso ao ensino superior público, a partir do princípio de mérito, é uma discussão importante. Dessa forma, o princípio de mérito conjuga dois fatores: o esforço e o resultado. Ao pensar-se na hodierna forma de ingresso ao ensino superior público, por meio dos vestibulares tradicionais, pode-se dizer que o que ele leva em consideração é somente o resultado de uma avaliação, e não o esforço do estudante para chegar até o momento de prestar a prova, toda a sua dedicação pregressa. Veja-se que aqui está sendo ponderado o resultado, e não o esforço, pois quem acerta mais questões, ou "vai melhor" na prova efetivamente, é selecionado. O que se busca pensar e questionar é porque não um sistema que leve sim em consideração o tanto que o candidato teve que percorrer para chegar ao momento de tentativa de ingresso no ensino superior, e não somente se ele foi melhor do que outro em uma prova, mais ainda quando se fala em ensino superior público, em que o Estado tem papel relevante e em tese, por ser (essa educação) "sem custo", deveria beneficiar a parcela mais pobre da população, que não coincidentemente é justamente aquela que não consegue chegar a tal ensino, porque o ingresso se dá pelo resultado e não pelo esforço, - daí porque universidades públicas são povoadas por quem normalmente dispõe, ou disporia, de recursos financeiros para arcar com as custas de um curso superior. Enfim, essa é a discussão a que se dispõe este ensaio a retratar: o esforço, o resultado, o mérito, e a (in)justiça nas formas atuais de acesso ao ensino superior público. Ainda há um longo caminho a se percorrer nessa discussão, porque é fatidicamente o mérito um assunto espinhoso, mas somente o fato de se poder questionar, e ponderar possíveis mudanças, já denota o quanto se pode evoluir no argumento.

Relativamente ao mérito ponderado por John Rawls, quanto à pauta aqui invocada de forma de ingresso ao ensino superior público, parece claro que, de acordo com a "justiça como equidade" muito bem explicitada pelo pensador, não há nada de (equitativamente) justo, primeiro porque, hodiernamente, os cargos e posições estão de fato acessíveis a todos como o 


\section{A FORMA DE ACESSO AO ENSINO SUPERIOR NAS UNIVERSIDADES PÚBLICAS: JUSTIÇA, MÉRITO, ESFORÇO E OPORTUNIDADES}

autor propõe (pelo menos hipoteticamente), mas nunca, ousa-se dizer, em condições equitativas de oportunidades: equidade pressupõe igualdade material, pressupõe um senso de justiça que equipare os desiguais, e não que meça o seu valor em uma prova em um único dia, onde inevitavelmente quem teve melhores condições de preparação, por circunstâncias da vida, como o local de nascimento ou classe social, por exemplo, será beneficiado: isso parece partir do pressuposto de uma igualdade formal, em que todos são iguais, e, definitivamente, nem todos são iguais. Reitera-se: condições equitativas de oportunidades. Tanto é assim, que Rawls ${ }^{20}$ (2003, p. 61) esclarece:

[...] devemos voltar nossa atenção para o significado de igualdade equitativa de oportunidades. Trata-se de uma noção difícil e não totalmente clara; talvez sua função possa ser inferida das razões pelas quais ela é introduzida: para corrigir os defeitos da igualdade formal de oportunidades - carreiras abertas a talentos - no sistema da chamada liberdade natural (Teoria, $\S \S 12$ e 14). Para tanto, diz-se que a igualdade equitativa de oportunidades exige não só que cargos públicos e posições sociais estejam abertos no sentido formal, mas que todos tenham uma chance equitativa de ter acesso a eles. Para especificar a ideia de chance equitativa dizemos: supondo que haja uma distribuição de dons naturais, aqueles que têm o mesmo nível de talento e habilidade e a mesma disposição para usar esses dons deveriam ter as mesmas perspectivas de sucesso, independentemente de sua classe social de origem, a classe em que nasceram e se desenvolveram até a idade da razão. Em todos os âmbitos da sociedade deve haver praticamente as mesmas perspectivas de cultura e realização para aqueles com motivação e dotes similares. [...] A sociedade também tem de estabelecer, entre outras coisas, oportunidades iguais de educação para todos independentemente da renda familiar $(\S 15)^{21}$. (grifo nosso)

Obviamente, John Rawls estabeleceu a justiça como equidade dentro de um plano ideal, e, inclusive, quanto aos menos favorecidos (conceito nuclear em sua obra) ele clarifica que "os indivíduos mais desfavorecidos são unicamente os indivíduos mais desfavorecidos em determinado esquema específico dentro de um esquema de cooperação" (2003, p. 84), porém, aqui busca-se fazer um exercício reflexivo à luz do explanado por John Rawls, e, evidentemente, por via de consequência, propondo-se uma análise ampliativa do fenômeno, a despeito de se tentar ao máximo respeitar os limites propostos pelo autor.

\footnotetext{
${ }^{20}$ Carlos Henrique Cardim, na apresentação do livro "O liberalismo político" (versão consultada de 2000), de John Rawls, explica que este autor, professor em Harvard, publicou, em 1971, o livro "Uma teoria da justiça" (como já exposto anteriormente). Na obra, John Rawls explanou a suposição de que "a justiça diria respeito ao conjunto da vida humana, e não apenas a um de seus segmentos". Assim, a justiça de Rawls repousaria em um princípio igualitário assim proposto: "todos os valores sociais - liberdade e oportunidade, progressos e riquezas e as bases do respeito a si mesmo - devem distribuir-se igualmente, a menos que uma distribuição desigual de quaisquer e de todos esses bens seja vantajosa para todos."

${ }^{21} \mathrm{O}$ autor mesmo esclarece que a ideia apresentada é "difícil" e esse é um esboço simplificado.
} 
Veja-se que, John Rawls relata, ao tratar da estrutura básica ${ }^{22}$ da sociedade que, a teoria da justiça como equidade cuida das desigualdades de perspectivas de vida dos cidadãos, suas expectativas em relação a toda a vida, considerando-se os bens primários ${ }^{23}$. Para tanto, ele relaciona que as perspectivas são afetadas por três tipos de contingências ${ }^{24}$, quais sejam: a classe social de origem; os talentos naturais e as oportunidades que se tem de desenvolvimento desses talentos em função da classe ou origem; e, por fim, sua boa ou má sorte ao longo da vida. Tais contingências ligam-se intimamente ao discutido aqui, acerca da justiça ou injustiça no sistema brasileiro de ingresso no ensino superior público por meio do vestibular, uma vez que, o próprio autor menciona que elas afetam o conteúdo dos fins últimos das pessoas, e o vigor e a confiança com que procuram realizá-los (ousa-se dizer que eles alteram inclusive a autoestima do cidadão, também construída a partir do olhar do outro). Ainda, o autor menciona claramente que a avaliação das pessoas para as suas perspectivas de vida é feita segundo o lugar de cada qual na sociedade e os objetivos são formulados à luz dos meios e oportunidades de que se pode dispor de forma realista. Veja-se o quanto é relevante o mencionado para a construção de um conceito de mérito ou mesmo de definição de justiça, a despeito de não se estar na sociedade atual na posição original proposta pelo autor em suas obras.

Aqui, retoma-se sucintamente a ideia de mérito em John Rawls, no que concerne à distribuição dos talentos naturais como bem comum. É claro que, não se parte do ideal de merecimento para averiguar o lugar das pessoas na distribuição dos talentos naturais, até porque ninguém merece ou deixa de merecer nascer mais abastado do que outro, nascer homem ou mulher, ou nascer nesse ou naquele local. O que é imprescindível que se mencione na ideia de Rawls (e o autor cita, é claro, dentro da ideia da estrutura básica de acordo primário exposta

22 Conforme John Rawls (2003, p. 13-14), a estrutura básica da sociedade coaduna-se na maneira como as principais instituições políticas e sociais da sociedade interagem, de modo a formar um sistema de cooperação social, e a forma como são distribuídos direitos e deveres básicos e determinada a divisão das vantagens oriundas da cooperação social durante o passar do tempo. O autor cita a Constituição política com um judiciário independente, as formas legalmente reconhecidas de propriedade e a estrutura da economia (meios de produção democráticos), e até mesmo a família como partes da estrutura básica. Assim, para ele, a estrutura básica é o contexto da sociedade onde as atividades de associações e de indivíduos acontecem.

${ }^{23}$ Sobre os bens primários, reitera-se o exposto alhures: John Rawls se volta para o conceito de "menos favorecidos" na parte II, $\S 17$, da obra "Justiça como equidade: uma reformulação", especificamente entre as páginas 81 e 86 e liga, em síntese, a ideia de menos favorecidos à ideia de acesso a bens primários - direitos e liberdades básicas; liberdades de movimento e de livre escolha de ocupação sobre um fundo de oportunidades diversificadas, oportunidades estas que propiciam a busca de uma variedade de objetivos e tornam possíveis as decisões de revê-los e alterá-los; os poderes e prerrogativas de cargos e posições de autoridade e responsabilidade; renda e riqueza; e bases sociais e autorrespeito, entendidas como aqueles aspectos das instituições básicas normalmente essenciais para que os cidadãos possam ter um acesso vívido de seu valor enquanto pessoas e serem capazes de levar adiante seus objetivos com autoconfiança. (grifo nosso).

${ }^{24}$ Não há a menção à raça ou gênero pois John Rawls parte da ideia de uma teoria ideal. 
por ele próprio) é que a concepção do princípio da diferença visa a recompensar as pessoas, “não por seu lugar na distribuição, mas por treinar e educar seus talentos, e colocá-los em prática a fim de contribuir para o bem tanto dos outros como próprio" (RAWLS, 2003, p. 106). Perceba-se que, para o autor, quando as pessoas agem assim são merecedoras, como exige a ideia de expectativas legítimas. "A ideia de titularidade pressupõe, assim como as ideias de mérito (moral), um esforço deliberado da vontade, ou atos realizados intencionalmente. Enquanto tais, fornecem a base das expectativas legítimas." (RAWLS, 2003, p. 106).

Evidente que, alguém que não percebe a realidade à luz da teoria de Rawls poderia pensar e argumentar que atualmente não se vive em um plano ideal, e ninguém se encontra sob o véu da ignorância, de modo que todos conhecem o "seu lugar" no mundo e seria impróprio pensar-se a realidade atual à luz da justiça como equidade sem se estar na posição original pensada pelo autor. De fato, o exercício interpretativo aqui parece ser um tanto ampliativo ${ }^{25} \mathrm{da}$ teoria de Rawls, mas, é nítido que caso as pessoas fossem transportadas para a posição original, e cobertas pelo véu da ignorância, concordariam: tratar todos de maneira formalmente igual para o alcance de oportunidades não seria equitativamente justo, as pessoas não são iguais, e todas as contingências e peculiaridades devem ser levadas em consideração - até porque sob o véu da ignorância nenhuma pessoa saberia sua classe social, raça, sexo e/ou gênero, e certamente lutaria pela igualdade material de tratamento dos desiguais, e até porque, não parece plausível que se imagine que a forma atual de acesso ao ensino superior público é justa com os menos favorecidos (inclusive na perspectiva Rawlsiana).

Assim, parece ser nítido que, caso tomada a justiça como equidade de John Rawls em seus pontos principais, o hodierno meio de acesso ao ensino superior público não parece equitativamente justo, porque não respeita os princípios de justiça estabelecidos por ele, e porque parte da ideia de um mérito advindo unicamente de resultado, o que não parece ser o defendido. Deixa-se claro, porém, que essa foi a interpretação feita pela autora do presente texto para o assunto em questão, coadunando-o à teoria de John Rawls, de modo que, não necessariamente fosse esse o posicionamento do autor especificamente sobre o tema.

Muito bem, veja-se: como mencionado anteriormente, a política de cotas efetivamente emergiu para tentar o melhoramento da desproporcionalidade delineada ao longo do texto, e a esperança é que ela o faça, apesar de ainda hoje a universidade pública parecer segregar, em

\footnotetext{
${ }^{25}$ A despeito de, como referido alhures, poder-se, a qualquer tempo, voltar-se à posição original para reflexão, uma vez que esta não é um ponto fixo inicial, como bem ponderado por John Rawls.

Rev. de Teorias da Justiça, da decisão e da argumentação jurídica | e-ISSN: 2525-9644| Evento Virtual| v. 6 | n. 1 | p. 37-54| Jan/Jun. 2020 
que pese toda a evolução que se vem construindo. Assim, toma-se aqui a liberdade de transcrever as palavras de Oscar Vilhena, da $\operatorname{CONECTAS}^{26}$, quando da emissão de sua opinião acerca das cotas raciais na Arguição de Descumprimento de Preceito Fundamental n. 186 (ADPF das cotas - UnB), que ainda soam muito atuais embora as cotas já tenham sido, pelo menos em tese, implementadas:

"[...] as ações afirmativas ajustam aquelas condições que não foram dadas a determinados setores, para que todos possam concorrer em igualdade de condições. $\mathrm{O}$ acesso à educação universitária deve ser segundo a capacidade, mas o nosso vestibular não mede a capacidade, mede o investimento".

Mas, então, para além das cotas (que já buscam fazê-lo), o que poderia ser efetivamente feito pelas instituições públicas para considerar a caminhada do estudante, o seu ponto de partida e toda a trajetória percorrida? Democratizar o acesso, formalizar processos de seleção que incluam entrevistas presenciais com os candidatos, a fim de conhecê-los e conhecer suas histórias, verificar as habilidades específicas dos candidatos e relacioná-las ao curso pleiteado, realizar testes padronizados, solicitar envios de cartas de recomendação e de redações ${ }^{27}$, proceder a análise do currículo acadêmico do candidato, ou até mesmo a concessão de bolsas àqueles que, mesmo não precisando arcar com os custos de uma mensalidade, não conseguiriam manter-se (economicamente falando) tendo em vista as outras despesas que um curso universitário exige.

Finalmente, forçoso mencionar que a crítica aqui referida pauta-se na análise conjuntural do sistema, de forma que não se teve o intento de questionar uma ou outra instituição. Ademais, como reiterado, as ações afirmativas tomadas já há algum tempo vêm, em certa medida, corroborando para o desfazimento do padrão de mérito calcado no resultado

${ }^{26}$ A CONECTAS é uma organização não governamental que busca, segundo se colhe do próprio sítio eletrônico
da entidade, proteger, efetivar e ampliar os direitos humanos. Possui ações para fortalecimento do espaço
democrático, envolvendo também desenvolvimento e direitos socioambientais (CONECTAS, 2020).
${ }^{27}$ Esses são exemplos de verificação da trajetória do candidato utilizados comumente por instituições
estadunidenses, a exemplo da mundialmente conhecida Universidade Harvard. Mais informações sobre Harvard e
o modo de acesso podem ser encontradas no próprio sítio eletrônico da universidade. Por exemplo, para a admissão
na Harvard Law School, vários fatores são levados em consideração, tais quais: experiência de trabalho e liderança
demonstrada, qualidades como energia, ambição, bom-senso, capacidade de superação de adversidades, ideais
estabelecidos pelo candidato e preocupação com o bem-estar das outras pessoas. Assim, são reconhecidas não
somente habilidades acadêmicas, mas qualidades que contribuam com a diversidade de perspectivas e experiência,
qualidades gerais e vitalidade. Há o incentivo à diversidade, às solicitações de ingressos de negros, mulheres,
pessoas de origens socioeconômicas menos favorecidas, pessoas com deficiência, membros de grupos
historicamente sub-representados, e aqueles que se interessam em servir comunidades comumente tidas por sem
recursos e representações legais (HARVARD LAW SCHOOL, 2020). Rev. de Teorias da Justiça, da decisão e da argumentação jurídica | e-ISSN: 2525-9644| Evento Virtual| v. 6 | n. 1 | p. 37-54| Jan/Jun. 2020 
(unicamente) nesses casos, na busca por uma distribuição equitativa de oportunidades, mas, pensa-se que o caminho ainda é longo, e válida é a crítica.

\section{CONCLUSÃO}

A ideia do presente ensaio é a reflexão. Refletir demanda conhecer, e mais do que isso, demanda quase sempre questionar: questionar a realidade posta, questionar uma doutrina, questionar uma teoria, enfim, buscar explicações. No caso, a tentativa de reflexão partiu da análise da realidade, questionando-a a partir do ideal de justiça e de mérito. O raciocínio foi construído com base em autores específicos de modo que, inicialmente, então, a busca foi pelo entendimento da justiça e do mérito com base no ideal deles, e, após, o estudo afunilou na busca pela concretização dos seus objetivos - questionar o acesso ao ensino superior público. Seria ingenuidade imaginar que o assunto pudesse ser exaurido, a maior porque a justiça é ponderada de diferentes formas por diferentes autores, e, depois, porque mesmo especificamente dentro do tema existem controvérsias de diversas ordens. O que se tentou, então, retomando a proposta inicial, foi refletir, questionar, ponderar, instigar, a partir de alguns parâmetros estabelecidos, e dos autores pesquisados.

Nesta senda, entende-se, como reiterado ao longo do texto que, o acesso ao ensino superior público no Brasil, embora esteja de certo modo evoluindo, ou pelo menos se transformando, até mesmo pela utilização das ações afirmativas (cotas), ainda é, infelizmente, de certa forma etilista, não de per si, mas porque o mérito pelo resultado em regra é alcançado primordialmente pela "elite" branca, de classe média-alta e nada periférica geograficamente falando.

Por tal motivo é que se buscou fazer, ao longo do texto, o questionamento acerca da possibilidade de que o mérito pelo esforço seja sempre que possível priorizado, ou pelo menos levado em consideração.

Sonhar com um mundo sem desigualdades é utópico. Elas existem e ao que parece, não perecerão. Aliás, como bem estatuído por Rawls (2003, p. 60), de certo modo, pode ser até mesmo que elas "possam" existir (para ele as desigualdades sociais e econômicas existem e podem existir devendo satisfazer duas condições, a primeira é que os cargos e posições sejam acessíveis a todos em condições de igualdade equitativa de oportunidades, e a segunda é que elas devem beneficiar ao máximo os menos favorecidos da sociedade envolvida). Mas, sonhar

Rev. de Teorias da Justiça, da decisão e da argumentação jurídica | e-ISSN: 2525-9644| Evento Virtual| v. 6 | n. 1 | p. 37-54| Jan/Jun. 2020 
com a equidade é necessário, é empoderador. Por isso é que se buscou propô-la relativamente ao acesso ao ensino superior público. A diversidade é linda, é engrandecedora, conviver com o "diferente" desperta humanidade, e as universidades públicas são, talvez, o local mais apropriado para tanto. Que se tenha, então, cada vez mais: negros e brancos, "ricos" e "pobres", interioranos e nascidos em capitais, todos minimamente em pé de igualdade (substancial) dividindo os mesmos sonhos. Que se tenha, consequentemente, mais médicos negros, mais engenheiros advindos de classes sociais "menos favorecidas", mais advogados outrora moradores de periferias e que desde sempre se consideraram "arrimo de família" (exemplificadamente), enfim: que o padrão seja desconstruído. "Sonhemos”!28

\section{REFERÊNCIAS}

BARRY, Brian. Theories of Justice. Berkeley: Universidade da Califórnia, 1989.

BRASIL. Constituição: República Federativa do Brasil de 1988. Brasília, DF: Senado Federal, 1988.

Decreto n. 7.824, de 11 de outubro de 2012. Disponível em:<

http://www.planalto.gov.br/ccivil_03/_ato2011-2014/2012/decreto/d7824.htm>. Acesso em: 23 jan. 2020.

Lei 12.711, de 29 de agosto de 2012. Disponível em:<

http://www.planalto.gov.br/ccivil_03/_ato2011-2014/2012/lei/112711.htm>. Acesso em: 23 jan. 2020.

BRASIL. Supremo Tribunal Federal. Arguição de Descumprimento de Preceito

Fundamental. Relator: Ministro Ricardo Lewandowski. Proc. n. ADPF 186. Decisão em 26 abr. 2012. Disponível em:

$<$ http://redir.stf.jus.br/paginadorpub/paginador.jsp?docTP=TP\&docID=6984693>. Acesso em: 24 jan. 2020.

CONECTAS DIREITOS HUMANOS. Quem somos?. 2020. Disponível em:< https://www.conectas.org/quem-somos/>. Acesso em: 27 jan. 2020.

DECLARAÇÃO UNIVERSAL DOS DIREITOS HUMANOS. Assembleia Geral das Nações Unidas. 10 dez. 1948. Disponível em: < https://nacoesunidas.org/wpcontent/uploads/2018/10/DUDH.pdf> . Acesso em: 5 nov. 2019.

ESALQ - USP. Perfil dos ingressantes 2019. 2019. Disponível em:< http://www.esalq.usp.br/acom/docs/ingressantes_2019.pdf>. Acesso em: 22 jan. 2020.

\footnotetext{
${ }^{28}$ Pelo modo de argumentação exposto, entendeu-se imprescindível a redação da frase na primeira pessoa do plural.

Rev. de Teorias da Justiça, da decisão e da argumentação jurídica | e-ISSN: 2525-9644| Evento Virtual| v. 6 | n. 1 | p. 37-54| Jan/Jun. 2020
} 
EXAME. No Enem, 1 a cada 600 alunos pobres consegue ficar entre os melhores. 2019. Disponível em: $<$ https://exame.abril.com.br/brasil/no-enem-1-a-cada-600-alunos-pobresconseguem-estar-entre-os-melhores/>. Acesso em: 22 jan. 2020.

FIGUEIREDO, Argelina Cheibub. Princípios da Justiça e avaliação de políticas. Lua Nova: Revista de cultura e política, n.39, São Paulo. 1997.

GUIA DO ESTUDANTE. Conheça os principais processos seletivos para o ensino superior. 2018. Disponível em: <

https://guiadoestudante.abril.com.br/universidades/conheca-os-principais-processos-seletivospara-o-ensino-superior/>. Acesso em: 19 jan. 2020.

HARVARD LAW SCHOOL. Apply to Harvard Law School. 2020. Disponível em:< https://hls.harvard.edu/dept/jdadmissions/apply-to-harvard-law-school/>. Acesso em: 25 jan. 2020.

MILLER, David. Justice. The Stanford Encyclopedia of Philosophy (Fall 2017 Edition). 2017. Disponível em: <https://plato.stanford.edu/archives/fall2017/entries/justice/>. Acesso em: 19 jan. 2020.

MINISTÉRIO DA EDUCAÇÃO. Entenda as cotas para quem estudou todo o ensino médio em escolas públicas - perguntas frequentes. 2012. Disponível em:<http://portal.mec.gov.br/cotas/perguntas-frequentes.html>. Acesso em: 23 jan. 2020.

Portaria Normativa n. 18, de 11 de outubro de 2012. Disponível em:< http://portal.mec.gov.br/cotas/docs/portaria_18.pdf>. Acesso em: 23 jan. 2020.

PROTOCOLO ADICIONAL À CONVENÇÃO AMERICANA SOBRE DIREITOS HUMANOS EM MATÉRIA DE DIREITOS ECONÔMICOS, SOCIAIS E CULTURAIS, "PROTOCOLO DE SAN SALVADOR". Comissão Interamericana de Direitos Humanos Organização dos Estados Americanos. 17 nov. 1988. Disponível em:

$<$ http://www.cidh.org/Basicos/Portugues/e.Protocolo_de_San_Salvador.htm >. Acesso em: 24 jan. 2020.

RAWLS, John. Justiça como equidade: uma reformulação. Tradução Claudia Berliner. 1. ed. São Paulo: Martins Fontes, 2003. Tradução de: Justice as fairness: a restatement.

O Liberalismo Político. Tradução Dinah de Abreu Azevedo. 2. ed. São Paulo: Editora Ática, 2000. Tradução de: Political Liberalism.

SIQUEIRA, Ivan. JORNAL DA USP ESPECIAL. Universidade pública: mérito ou oportunidade?. Disponível em:<https://jornal.usp.br/especial/universidade-publica-meritoou-oportunidade/>. Acesso em: 24 jan. 2019. 